\title{
1. A connected approach to learning in higher education
}

\section{Ruth Bridgstock and Neil Tippett}

\section{INTRODUCTION}

Connectedness has always been central to peoples' lives and careers. Terms such as co-operation, collaboration, communication, and persuasion refer to specific aspects of connectedness, which encapsulate the spectrum of person-to-person interactions that shape our daily lives. A substantial body of literature spanning the last 70 years documents the individual, social and cultural benefits that connecting with others brings (Lewis, 1953; Manderson, 1948; Reis, 1984), improving our life satisfaction, and enhancing wellbeing. Equally, connectedness allows us to prosper in our career pathways by boosting productivity, improving our confidence, finding us opportunities, and supporting our skill and knowledge development (Argyle, 1981; Friend and Cook, 1992).

Seminal work by educational theorists such as Berger and Luckmann (1966) explored the social construction of knowledge and learning, investigating how a more social approach to teaching could support educational outcomes; however, the development of social capabilities remained largely implicit in higher education curricula until the early 1990s (Johnson and Johnson, 1990). The last two decades have seen a greater recognition of the importance of social interaction to learning in higher education, evidenced by universities' increasing focus on developing their learners' social capabilities. Curriculum emphases have shifted towards promoting not only disciplinary and technical capabilities, but also transferable skills that can be applied in many different contexts (Clanchy and Ballard, 1995). Capabilities such as communication, collaboration and teamwork have become ubiquitous in university courses, emerging as some of the most valuable, and yet tacit and often difficult to teach, skills that learners from every discipline develop during their time at university.

Extending from several decades of research into social learning in formal educational environments, in the 1990s scholars started to explore learning 
that occurred through informal and networked social mechanisms. Lave and Wenger's (1991) seminal work on communities of practice contributed significantly towards a broad recognition of learning processes that occur through informal participation in shared practice. By the early 2000s, with the rise of social media, educators started to acknowledge the roles that digital networks play in learning, and the importance and distinctiveness of communication and collaboration in digital contexts. For connectivist learning theorists (Downes, 2005; Siemens, 2005), knowledge is distributed across a network of connections, and learning consists of the ability to navigate and make sense of those networks.

This book acknowledges that all contemporary universities appreciate the importance of developing learners' social capabilities, and that all universities teach using social methods to some extent. However, we argue that higher education social teaching practice is hindered by the bounded nature of institutional policies and structures, which preclude wider partner interaction, and traditional approaches to teaching, which emphasise content knowledge and transmissive pedagogies. It is very hard for us to collaborate across disciplines, with researchers or with other organisational units inside the institution, let alone move beyond institutional boundaries to engage with professional, industry and community connections for teaching. We are doing ourselves and our learners a disservice by not doing so.

Learning is something that naturally and optimally happens in ecologies and informal communities (Bridgstock, 2017; Mitchell and Sackney, 2011). In the digital age, learning is also highly networked, occurring through extended and diverse connections with people, systems and information (Siemens, 2005). As educators, we need to be fostering both communities and networks for learning, and the capabilities that learners will need in order to make the most of these in their lives and work. If we are to achieve this, teachers must become much better connected, and so must our institutions.

Building upon existing knowledge and practices, this volume encourages a step-change in the way that we think about teaching in higher education by introducing the Connectedness Learning Approach. The Connectedness Learning Approach was developed by the first author in conjunction with a large number of university educators, industry and community partners, and students/graduates during the course of an Australian National Senior Teaching Fellowship. The Connectedness Learning Approach argues that by using socially networked, connected activities such as mentoring, collaborative problem-solving, crowdsourcing and networked learning, in partnership with industry and community where relevant, we have the potential to achieve far more in education than we could by 'going it alone'. Through ten cases of practice, this volume examines empirically how higher education can foster learner and institutional connectedness, exploring organisational structures, 
processes and practices, pedagogical approaches, and the capabilities themselves which can best help learners succeed in their learning and beyond.

This introductory chapter presents a background to the Connectedness Learning Approach, focusing on how connectedness can benefit us in our lives and work roles. It examines how twenty-first century influences, such as globalisation, super-complexity, the innovation economy and the digitally networked world necessitate the development of new capabilities to meet ever changing workplace demands. The chapter then discusses the role that connectedness plays in current teaching practice, and the reasons that development of connectedness learning in higher education is necessary.

Against this background, the second half of this chapter sets out how the Connectedness Learning Approach can be used in higher education to support learners in building, maintaining and making the most of their networks and social relationships for life and career. The approach takes a systems perspective, describing learners' connectedness capabilities, and then exploring associated pedagogic approaches and institutional-enabling strategies that facilitate their development. The background and phases of research that have guided the development of this approach are outlined, accompanied by a brief description of the process through which this volume has been prepared. Finally, the chapter briefly introduces ten conceptual and empirical investigations, employed across a variety of higher education contexts. These investigations emphasise how different elements of the approach can be used by universities to foster connectedness. Through these chapters, the volume presents an authentic and relevant account of how we can embed connectedness into learning and teaching.

\section{WHY IS CONNECTEDNESS IMPORTANT?}

The ways in which we interact with others can have a profound impact on our daily lives, affecting our individual and community health and wellbeing, our potential to enact social change, our learning and career development, and our productivity at work (Bridgstock, 2019a). It is worth noting up front that in recent times, the shape, functioning and use of social networks have all shifted dramatically under the influence of digital tools and social media. Strong ties have seen the least change in the digital age; most people still typically have 7-12 individuals with whom they interact in an ongoing manner, and with whom they maintain high levels of trust and intimacy. However, our ability to develop weak and indirect ties has expanded greatly through digital networks, potentially increasing the social sphere of influence. These digital networks offer us the potential to connect with hundreds, and in some cases, thousands more people, generating an expansive network of weak ties which allow for greater flow of information and resources (Kaplan and Haenlein, 2010). 


\section{Connectedness and Health and Wellbeing}

Maintaining strong social connections is predictive of positive health and wellbeing outcomes (Gadermann et al., 2016; Power et al., 2015). Connectedness is strongly linked to better mental health outcomes across the lifespan (Haslam et al., 2017); it has the potential to improve confidence, positive feelings, and life satisfaction (Jose, Ryan and Pryor, 2012), but can also insulate people from potentially harmful life experiences, including poverty and displacement as a refugee or asylum seeker (Mahoney and Siyambalapitiya, 2017).

With the advent of social media, it could be expected that social connectedness has increased, making us happier and healthier than ever before. However, studies suggest the relationship between social media use, social connectedness and wellbeing is more complex. While social media can make it easier to connect with others and create groups and communities, it can also become a source of alienation and ostracism for young people (Allen et al., 2014), providing a platform for negative online behaviours such as cyberbullying, which can negatively impact on our physical and mental health (Best, Manktelow and Taylor, 2014). Several studies have demonstrated a relationship between social media use, loneliness and depression (Utz and Breuer, 2017; Verduyn et al., 2017), however, the direction of causality is unclear. Negative experiences on social media have the potential to cause loneliness or depression, yet at the same time, lonely and depressed people may also be more inclined to seek social support online (Song et al., 2014).

Considering connectedness from a socio-cultural rather than individual perspective, an accompanying body of literature has explored the positive impact of social networks upon community wellbeing. Community wellbeing is described as "a state of being with others and the environment that arises where human needs are meet, where individuals and groups can act meaningfully to pursue their goals, and where they are satisfied with their way of life" (Armitage et al., 2012, p. 17). Social connectedness acts as a key driver of community wellbeing, with factors such as community spirit and cohesion, shared values, and social interaction each contributing towards the wellbeing of a community. In a connected community, people are more likely to volunteer, participate and share resources, and correspondingly, those communities will be more resilient in the face of natural disasters and other rapid changes (McCrea, Walton and Leonard, 2016). Communities that are cohesive and well-connected offer greater levels of support, sharing of resources, and the potential to restore and maintain a state of positive wellbeing for all community members. 


\section{Connectedness and Social Change}

Social connectedness can also be an effective vehicle for social change. Social networks have the potential to fulfil collective interests by catalysing purposive action (Coleman, 1990). Often termed civic participation or engagement, purposive action is co-operative behaviour undertaken by multiple members of a social network in unison. This type of action usually has a far greater impact than solitary actions taken by one individual. Whether purposive action occurs at the level of the community or as a social movement, this form of change is usually initiated through communication between individuals with a shared desire to enact social change. With the advent of the Internet, opportunities to communicate and connect with others who share the same beliefs have expanded exponentially, leading to rapid spread across communities, and inspiring global movements, such as the prolonged protests that occurred during the Arab Spring (Castells, 2015). Despite this, social media alone is not a panacea for social movements - it has also given rise to so-called 'slacktivism', where people support an organisation or movement on social media without taking any action beyond this.

\section{Connectedness for Career Development}

The positive effects of social capital and networking behaviour on different aspects of career development are well documented. For instance, Jackson (2014) demonstrated, using national modelling of graduate destinations statistics, that graduates who used social capital-based approaches to acquire work had far more positive initial graduate outcomes than those who did not. Networking comprises the acquisition and strengthening of ties. Its long-acknowledged benefits include increased access to resources, information, career opportunities, sponsorship and support (Duncan and Dunifon, 2012; Seibert, Kraimer and Liden, 2001). With changes to the structure of the labour market, the 'gig economy' and the decline of the traditional organisational career, networking is arguably more important for one's career development now than it ever has been. Many people are now engaging in portfolio careers, using their networks and social capital to recurrently seek out new career opportunities. In the current era of LinkedIn and SEEK, many of these career development functions have moved online. Employers and recruiters now routinely screen potential employees using social media and search engines. In a survey of American recruiters, Lancaster (2016) found 91 per cent had used social media as an applicant screening tooling, and 7 in 10 had made positive recruitment decisions based on information posted on social networking sites. 
Connectedness also fosters productivity at work. As one example, advanced economies are increasingly finding value in the creation and production of new knowledge. Innovation and enterprise are fuelled through social interactions, benefitting from collaborative, complex social environments which offer an active combination of people, knowledge and resources (Mascia, Magnusson and Björk, 2015). Creativity can be fostered through exposing individuals to new ideas and processes, particularly those that span disciplinary, institutional or geographical boundaries (Granovetter, 2005), with social networks acting as mechanisms through which creative ideas can be integrated, implemented, and brought to fruition (Tocher, Oswald and Hall, 2015). Social networks also provide opportunities for individual enterprise, opening access to new markets or resources. In contrast to the closed, organisationally-based knowledge production of previous times, innovation is becoming more and more 'open' (Chesbrough, Vanhaverbeke and West, 2006), that is, autonomous, diverse and decentralised.

\section{Connectedness for Learning}

Much of learning is inherently social, and the roles that social relationships and networks play in professional and lifelong learning are of great relevance to universities that wish to strengthen the employability of their graduates (Field, 2009). Valuable learning is achieved through situated practice that is embedded into an informal framework of social support and development. Informal social learning processes include expert modelling, mentoring, explicit instruction, advice and feedback. In the workplace, these processes are all-pervasive, fostering ongoing professional learning and organisational acculturation (Billett, 2008; Boud and Middleton, 2003; Lave and Wenger, 1998). Face-to-face learning strategies tended to be employed along the lines of a community of practice or enquiry (Lave and Wenger, 1998), involving active relationship building between individuals with similar interests. Communities of practice often rely on strong ties and involve repeated and extended reciprocal interactions.

We all learn from 'weak tie' connections outside our communities of practice as well. Social media and digital networks have become central to our lives over the last few years, and for many these have helped to expand the reach of wider networks in helping people learn new capabilities and keep up to date with trends of interest (Bridgstock, 2017). Online modes of social informal learning can take the form of a distributed learning network of professionals and other interested people (Albors, Ramos and Hervas, 2008), in which people may not even know the people with whom they are interacting, or know them only slightly. Networked informal learning through social media can be used to obtain on-demand, 'just in time' quick-turnaround information. 
Professionals obtain the information quickly, and then pass it along by sharing or retweeting. The power of digital networks for informal, personalised learning can be considerable. In order to take advantage of this power, learners must possess the critical capacity to (a) select where and how to go online to learn; (b) filter data for credibility and usefulness; and (c) synthesise it with existing knowledge (Bridgstock, 2017).

Digital networks can also be used for other forms of learning which rely on weak or indirect ties, such as collective intelligence, and crowdsourced approaches to learning (Leimeister, 2010), the most prominent example of which is Wikipedia. Social media has now made it possible to draw upon the collective expertise of an entity ('the crowd') comprising many diverse individuals with many different capabilities, to solve complex problems which could not be answered individually (Albors, Ramos and Hervas, 2008). This kind of networked learning allows for the creation of group-based socially constructed skills and knowledge that develop and evolve over time. Each individual in the network draws from their own perspectives, capabilities and approaches, and in turn adapts to, and learns from, their circumstances and contexts (see for instance Engestrom, 2001; Lave and Wenger, 1998). As a result, such larger networks represent a confluence of varying skills, experiences and perspectives, fostering knowledge and capabilities which are broader and more adaptable than the skills we would be able to develop as individuals. As an example of this, the Foldit multiplayer online game harnessed the complementary abilities of many thousands of players, who worked collaboratively to develop an assortment of new strategies and algorithms to predict complex protein structures (Cooper et al., 2010). Through the online game, gamers were able to solve a puzzle in less than three weeks that had eluded scientists using conventional methods for more than a decade.

\section{EMPLOYABILITY PLUS: WHERE DOES CONNECTEDNESS FIT IN HIGHER EDUCATION?}

Universities across the world are being tasked with preparing their students for the world of professional work. This enterprise has become increasingly difficult over recent years due to widespread labour market uncertainty and the massification of the higher education system in many Western countries (Tomlinson, 2012). In contrast to the previous era, in which ongoing professional work was virtually guaranteed for university-qualified individuals, contemporary graduates must be proactive and flexible, and have the capacity to adapt to a job market with continually shifting requirements (Clarke, 2008). It is said that rather than seeking security in employment, graduates must now seek security in employability. 
In this volume we take a pragmatic stance to the graduate employability agenda, accepting that learners, education institutions and policy makers alike are highly motivated for graduates to obtain positive employment outcomes. Employability is often operationalised as a graduate's ability to gain employment within a few months of course completion, a view which aligns with many national graduate outcomes survey measures. Instead we choose to take a broader conceptualisation of employability as encompassing a graduate's ongoing capacity to live and work productively and meaningfully in an increasingly dynamic and complex society (see also Fullan, 1993). Thus, we move beyond overly restrictive and often short-term definitions of employability which are limited to employment within a few months of course completion. For us, employability is the capacity to 'employ' one's 'abilities' - that is, the ability to harness one's skills, knowledge and other attributes in order to add value across a range of different contexts across the life course, including employment and career, as well as community and civic engagement.

Nearly all contemporary educational activity, including learning theory and research, is focused on developing the skills and capabilities of the individual person. This perspective is congruent with human capital theory, which considers the economic implications of the knowledge, skills and competences embodied within us as individuals, arguing that the more educated a population is, the more productive they will be (Olaniyan and Okemakinde, 2008). Traditionally, universities have sought to foster graduate employability primarily by developing their students' 'employability skills', 'graduate attributes' or 'graduate capabilities' through the curriculum (Yorke, 2006). Employability skills can be most commonly categorised into discipline-specific skills and knowledge, and transferable skills (skills and knowledge that can be transferred from one context to another). University policy documents often accompany these lists of employability skills with additional desirable qualities or attributes that employers may look for, including resilience, initiative, and grit/ determination.

Over the last five years, scholars have begun to acknowledge the importance of capital influences on employability. These capital influences can be thought of as the resources that the graduate brings to their employability journey, and have been suggested to include cultural, identity and social capital, as well as human capital (skills and knowledge) (Holmes, 2013; Tomlinson, 2017). Cultural capital refers to culturally valued knowledge, behaviours and dispositions aligned to the workplace. Identity capital relates to the graduate's ability to draw upon their experiences to develop a career self-concept and articulate a fruitful personal narrative relating to work (Tomlinson, 2017). Strongly related to connectedness, social capital represents the social relationships and networks that help graduates develop and mobilise their human capital for employability. 
Universities do acknowledge that socially-based activities, such as group or team work, are an important source of learning, and these are commonly incorporated into degree programs. Where used appropriately, group work can assist students in developing their capabilities for employability, including interpersonal communication skills, teamwork, negotiation, professionalism and self-regulation (Rossin and Hyland, 2003). However, in practice this approach often lacks authenticity. Assigning students from the same course to small groups to work on a problem in class is in many ways unrepresentative of how a group would function in the true working environment. Teamwork in the real world involves interacting with people from different disciplinary backgrounds, with different agendas and perspectives. In the real world, the problem is rarely presented neatly, with people assigned to roles, but can be highly emergent and both the aims and roles contested.

Recently, higher education has also started to embrace work integrated learning, service learning and other complex experiential learning approaches as a means of fostering and applying these capabilities and others (such as metacognitive self-regulation, emotional intelligence, and workplace cultural knowledge and skills) within an authentic environment. This is a very important step in fostering graduate employability more effectively. However, what is missing from the commentary of the benefits of these complex learning approaches is that they also offer the opportunity to connect with people beyond the classroom and university. Through the learning experience, students interact with others in productive ways, acquire new perspectives, build trust, and develop authentic professional and interest-based communities and networks. These relationships are just as important to their future lives as the individual skills the students acquire.

Digital networks can expand the reach of career development activities, with online social networking behaviour in particular having an enormous and increasing impact on the employability of graduates (Nikitkov and Sainty, 2014). While many graduates are well versed in the use of digital networks in their personal lives, studies suggest that relatively few at present possess the capabilities to exploit the opportunities for career development afforded through social media platforms, such as LinkedIn (Benson, Morgan and Filippaios, 2014; Bridgstock, 2019a). Many undergraduate students do not even think of digital networks as a valuable source of learning (Madge et al., 2009).

As an alternative and complementary perspective to the traditional skills-based approach used throughout higher education, the connected approach to learning outlined in this volume foregrounds the central roles of partnerships, groups, communities, and networks in order to better prepare students for their future lives and work. Addressing dimensions of learning and behaviour such as work integrated learning, learning through networks, 
and career development learning using authentic tools, The Connectedness Learning Approach considers the social and relational dimensions of learning, work and career, and how these can be successfully applied across higher education. With the increasing influence of social media, it also considers how these dimensions involve interactions and activities occurring within the digital space, both in addition to, but also instead of, face-to-face.

\section{HOW THIS VOLUME CAME TO BE: A CONNECTEDNESS LEARNING-BASED PROCESS}

This edited volume has its inception in an Australian National Senior Teaching Fellowship, Graduate Employability 2.0, undertaken in 2015-2016 at Queensland University of Technology by Ruth Bridgstock (see Bridgstock, 2019b). The fellowship sought to support the Australian higher education sector in fostering the capabilities of learners so that they were able to capitalise upon the affordances of digital and analogue social networks, both in life and work. The fellowship was constructed around four overlapping phases which together set out to: increase sectoral awareness of the importance of social network capabilities to graduate employability; increase knowledge of effective ways to develop these skills; and, increase inclusion of social network capability development in higher education learning and teaching.

\section{Phase 1: Research}

The initial phase of the fellowship offered the opportunity to empirically establish a connectedness learning approach in higher education. It asked which learning and teaching approaches were best suited to fostering students' capabilities and networks, and which institutional-enabling strategies were fundamental to supporting better networked learning and teaching. Additionally, by engaging with learning stakeholders across the higher education sector in Australia and beyond, the fellowship afforded the opportunity to increase understanding and adoption of connectedness learning and provide capacity-building opportunities and resources to support this. The fellowship commenced with a literature, policy and environmental scan to confirm the roles that digital and face-to-face relationships, networks and social capital play in graduate careers. Current higher education practice relating to this was examined using a combination of student surveys, interviews and case studies with educators, alumni and industry/community representatives. Together, this allowed for an assessment of the current 'state of play' concerning the connectedness of learners, programs and higher education institutions in Australia.

The findings from these Phase 1 activities offered a consistent picture around the connectedness of students, programs and universities, revealing a current 
oversight, but also a significant opportunity for higher education. The most apparent finding centred around the professional networks of undergraduate students and early graduates, which could be described as embryonic at best. Students appeared to lack confidence in their connectedness capabilities, particularly when it came to establishing and growing professional connections, and also struggled in negotiating networked behaviour online. Based upon the empirical work conducted as part of the Fellowship, connectedness learning seemed to remain a tacit and largely post-graduation process. Although alumni and industry interviewees both emphasised the importance that social networks and social network capabilities were able to bring to graduates' professional lives, connectedness learning was either lacking or entirely absent in many Australian higher education programs. Interviews and case studies with teachers and institutional leaders identified the difficulties that educators faced in developing effective and sustainable networks or collaborations with industry stakeholders, as well as with other learning and teaching partners. In part, these difficulties were often attributed to the strongly entrenched legacies of organisational structures, processes, cultures and philosophies that beset higher education institutions.

Students' social networks were found to largely be formed through socialising with peers (Madge et al., 2009), part-time employment, internships, extra-curricular activities, school networks and family members' contacts (Clark et al., 2015). While the interviews unearthed a few cases of exemplary connectedness learning practice, this was not widespread among participants nor universities, and was not systematic or integrated within institutions. Exemplary practice included work integrated learning programs (such as internships or industry projects), and to a lesser extent, alumni engagement initiatives, industry guest teaching, development of LinkedIn profiles and co-curricular leadership and recognition programs. When asked why the prevailing approaches to learning and teaching showed such an apparent disconnect, participants indicated: (1) a lack of top-of-mind awareness of the value of social networks to graduate success, including the absence of related concepts from institutional and course learning outcome lists; (2) the idea that teaching involving industry/community partnerships and connections beyond the university tends to be resource-intensive and associated with higher risk than classroom-based teaching; and lastly (3) because of large bureaucratic organisational structures and processes, which mean that universities were generally not set up to connect effectively with external or internal stakeholders for learning and teaching.

Participants often described these challenges in terms of two metaphors: the university as a 'walled garden', with teachers, learners and learning on the inside, and work, career and life on the outside; or alternatively, the university as a series of 'silos', with minimal exchange of knowledge or ideas and limited 
collaboration between organisational areas. Unlike university research and commercialisation activities, for learning and teaching there seems to be much less strategic or systematic development and management of external engagement and partnerships, such as client relationship management approaches.

\section{Phase 2: Developing the Connectedness Learning Approach}

The analysis and synthesis of the Phase 1 activities informed the development of a connected approach to university teaching and learning which could be applied across a variety of higher education contexts. Three outputs were developed: (1) a set of key principles that universities can use to implement connectedness learning; (2) a Connectedness Learning Model which summarises the individual capabilities, learning and teaching approaches, and institutional enabling strategies which support connectedness learning; and (3) a connectedness learning toolkit for educators. The initial prototype of the principles and Connectedness Learning Model were developed and progressively refined over the course of the fellowship, using input from all participants. In developing and refining these tools, the fellowship took a 'mind hive', socially networked approach. Essentially acting as a digitally-based crowdsourcing process, the mind hive approach utilised participants' collective expertise, enthusiasm and professional contacts by involving them in all aspects of the fellowship and offering each of them multiple routes through which to engage and contribute. As a result, the principles and Connectedness Learning Model are a representation of their combined knowledge and expertise, gathered over the course of the entire fellowship.

The 18 key principles offer a template which higher education institutions can use to effectively implement the Connectedness Learning Model. These principles form the basis of the analytical and evaluative elements of the practical connectedness toolkit for educators (www.graduateemployability2 -0. com) which was employed across varying higher education contexts in the capacity building phase of the fellowship. Developed according to the findings from Phase 1 of the fellowship, the 18 key principles for connectedness learning are:

\section{Connectedness capabilities}

1. Students have the opportunity to develop social connections and relationships.

2. Students develop one or more of the connectedness capabilities, particularly building a connected identity and identifying and growing new connections. 
3. Students develop skills in terms of career development learning, networked learning and/or collaboration for problem-solving or creating new knowledge.

\section{Connectedness pedagogies}

1. The learning is authentic and occurs in real professional contexts, involving professional activities and interactions with professionals. This could involve the use of open, industry-authentic tools and technologies.

2. Students co-design a learning experience that is meaningful for them.

3. Industry/community partners provide input into designing a learning experience that is meaningful for them.

4. Partners are carefully selected for alignment with student and program needs and will benefit from/find value in the partnership themselves.

5. Appropriate just-in-time resources and learning activities are provided to help students connect with networks effectively.

6. The program is tailored to partner, learning context and specific student needs.

7. Students maintain the connections they have made and continue to benefit from them, including having ongoing engagement with the program (e.g. as alumni).

\section{Enabling strategies}

1. The program is 'plugged in' to wider professional, industry and interest groups and networks.

2. The program seeks out and develops new relationships in a strategic way, according to principles of reciprocity.

3. The program deepens the relationships it has in effective ways, including through valuing its connections.

4. Interactions and communications are straightforward and effective.

5. Processes are simple and straightforward, with 'red tape' minimised.

6. Partnerships and networks within the university (intra-university connections) are present and optimised.

7. There are enough resources (people, workload, funding) to foster sustainable connectedness.

8. There is an evaluation plan in place that covers the above dimensions.

The second output of this phase was the Connectedness Learning Model (see Figure 1.1). This model summarises: (1) the capabilities that individuals require to make the most of their social connections; (2) the core learning and teaching approaches that were found to be most effective in developing student connectedness capabilities at the present time; and (3) the institutional-enabling strategies that helped to ensure the sustainable success of connectedness initiatives, and that the university itself was well 'networked'. The Connectedness 


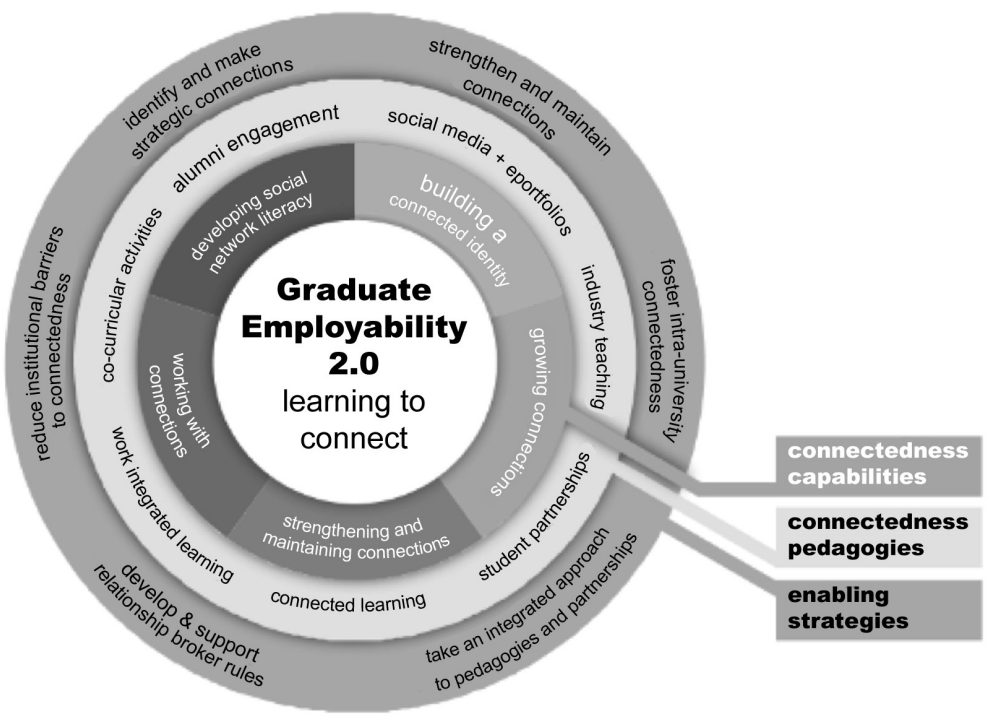

Figure 1.1 The Connectedness Learning Model

Learning Model is unpacked and explored in more detail in Chapters 2, 6 and 11 of the present volume.

The final output from Phase 2 was the connectedness learning toolkit for educators. The toolkit comprises reflective and evaluative tools that can be used to characterise and analyse the connectedness of students and programs; action-planning tools which can help educators to prioritise and strategize the development of connectedness in their programs; and a range of supporting resources, including capability frameworks, practice case studies and links to external resources and references.

\section{Phase 3: Capacity Building}

The final phase of the fellowship aimed to disseminate the research findings and share the principles, Connectedness Learning Model and toolkit across the higher education sector. By doing this, connectedness learning approaches were embedded at different levels of educational practice and policy across 18 Australian universities. Thirty-four engagement activities (including workshops, seminars, consultation and roundtables) were conducted across these 18 higher education contexts during the latter half of 2016, with nearly 1,200 tertiary educators joining the connectedness learning online network. 
Educators identified many opportunities through which they had been able to implement the Connectedness Learning Approach in their practice, including through curriculum design, reflective processes and strategic planning. The fellowship provoked a clearly identifiable change in the higher education sector. When surveyed a few months after the capacity building phase, more than eight in ten ( 81.5 per cent) participants had implemented some element or elements of the Connectedness Learning Approach in their institution. Furthermore, about 70 per cent of participants wanted to adopt connectedness learning more deeply, such as by enacting systemic and curricular changes, but required more time than the 12-month fellowship period to do so.

\section{Phase 4: Connectedness Learning Mentoring}

This volume is the culmination of a response to educators' requests that they needed more time and developmental support in order to embed the principles, Connectedness Learning Model and toolkit into their learning and teaching. In March 2017, a call for expressions of interest was sent out to educators and scholars through the connectedness learning online network, as well as via other scholarly distribution lists. The call asked for brief abstracts from teams in higher education institutions who wished to explore aspects of the Connectedness Learning Model in depth within their educational contexts and contribute their results towards an edited collection. More than 40 abstracts were received, with successful submissions chosen for diversity in subject matter, elements of the Connectedness Learning Model with which they had engaged, the quality of the submission, and the commitment of the team towards the volume development process.

Unlike typical edited volumes, this manuscript started development before any of the empirical work reported in the chapters commenced. A connectedness learning approach was taken throughout the process. All teams agreed to participate in mentoring and peer collaboration which covered their in-depth explorations and the writing up of results. Ruth Bridgstock visited each team in person at least once so they could share, develop and refine their work, and this was followed up with at least one or more online meetings with each team during the fieldwork. Once teams had findings to share, a Connectedness Learning Roundtable was hosted in December 2017. Each team attended and presented their work, then began the process of preparing their chapters, aided with mentoring from the editors, as well as each other. During the write up and editing phase, the editors met with each team twice via Skype, and also arranged a whole-of-group get-together to discuss shared challenges with development and writing. Chapter contributors worked developmentally in an ongoing way with other contributors to review and edit chapters, and we also called upon members of the wider network to provide fresh eyes on contribu- 
tions where they were needed. Throughout the process, contributors, editors and viewers alike were invited actively to speak back critically and constructively to the principles and Connectedness Learning Model, and to share their experiences of this within their chapters.

This volume ultimately provides the fruits of this labour: thirteen chapters, organised to correspond with the elements of the Connectedness Learning Model that they emphasise, moving from the inside of the Connectedness Learning Model towards the outside. The first section of this volume examines the individual capabilities required to connect with others for success in life and work, and how students can develop them. The second section engages with the learning and teaching approaches that lend themselves to enhancing the connectedness of learners, including work integrated and community-connected learning approaches. The third section engages with the institutional enabling strategies that universities can adopt to foster fruitful learning partnerships and networks with external and internal learning stakeholders, including industry, community, alumni, students, other organisational areas within the institution, and other educational providers. Together, these accounts, which span a wide variety of higher education contexts, set forth an authentic and relevant account of how higher education institutions can embed connectedness into their learning and teaching, and support their learners to acquire the knowledge, skills and capabilities to succeed in work and life.

\section{REFERENCES}

Albors, J., Ramos, J. C. and Hervas, J. L. (2008). New learning network paradigms: Communities of objectives, crowdsourcing, wikis and open source. International Journal of Information Management, 28(3), 194-202.

Allen, K. A., Ryan, T., Gray, D. L., McInerney, D. M. and Waters, L. (2014). Social media use and social connectedness in adolescents: The positives and the potential pitfalls. The Educational and Developmental Psychologist, 31(1), 18-31.

Argyle, M. (1981). Social Skills and Work. London: Routledge and Kegan Paul.

Armitage, D., Béné, C., Charles, A. T., Johnson, D. and Allison, E. H. (2012). The interplay of well-being and resilience in applying a social-ecological perspective. Ecology and Society, 17(4), 15-32.

Benson, V., Morgan, S. and Filippaios, F. (2014). Social career management: Social media and employability skills gap. Computers in Human Behavior, 30, 519-525.

Berger, P. and Luckmann, T. (1966). The Social Construction of Reality: A Treatise in the Sociology of Knowledge. Garden City, NY: First Anchor. 
Best, P., Manktelow, R. and Taylor, B. (2014). Online communication, social media and adolescent wellbeing: A systematic narrative review. Children and Youth Services Review, 41, 27-36.

Billett, S. (2008). Learning throughout working life: A relational interdependence between personal and social agency. British Journal of Educational Studies, 56(1), 39-58.

Boud, D. and Middleton, H. (2003). Learning from others at work: Communities of practice and informal learning. Journal of Workplace Learning, 15(5), 194-202.

Bridgstock, R. (2017). The university and the knowledge network: A new educational model for 21 st century learning and employability. In M. Tomlinson (ed.), Graduate Employability in Context: Research, Theory and Debate (pp. 339-358). London: Palgrave Macmillan.

Bridgstock, R. (2019a). Graduate Employability 2.0: Education for work in a networked world. In J. Higgs, G. Crisp and W. Letts (eds), Education for Employability: The Employability Agenda. Rotterdam: Sense-Brill Publishers.

Bridgstock, R. (2019b). Graduate Employability 2.0: Enhancing the Connectedness of Learners, Teachers and Higher Education Institutions. Final Report of the National Senior Teaching Fellowship. Canberra: Department of Education and Training.

Castells, M. (2015). Networks of Outrage and Hope: Social Movements in the Internet Age. Malden, MA: John Wiley and Sons.

Chesbrough, H., Vanhaverbeke, W. and West, J. (2006). Open Innovation: Researching a New Paradigm. Oxford: Oxford University Press.

Clanchy, J. and Ballard, B. (1995). Generic skills in the context of higher education. Higher Education Research and Development, 14(2), 155-166.

Clark, G., Marsden, R., Whyatt, J. D., Thompson, L. and Walker, M. (2015). 'It's everything else you do...': Alumni views on extracurricular activities and employability. Active Learning in Higher Education, 16(2), 133-147.

Clarke, M. (2008). Understanding and managing employability in changing career contexts. Journal of European Industrial Training, 32(4), 258-284.

Coleman, J. S. (1990). Foundations of Social Theory. Cambridge, MA: Harvard University Press.

Cooper, S., Khatib, F., Treuille, A., Barbero, J., Lee, J., Beenen, M. ... Popović, Z. (2010). Predicting protein structures with a multiplayer online game. Nature, 466(7307), 756-760.

Downes, S. (2005). An introduction to connective knowledge. Paper presented at Media, Knowledge and Education: Exploring New Spaces, Relations and Dynamics in Digital Media Ecologies, Innsbruck.

Duncan, G. J. and Dunifon, R. (2012). 'Soft-skills' and long-run labor market success. Research in Labor Economics, 35, 313-339. 
Engestrom, Y. (2001). Expansive learning at work: Toward an activity theoretical reconceptualization. Journal of Education and Work, 14(1), 133-156.

Field, J. (2009). Learning transitions in the adult life course: Agency, identity and social capital. In B. Merrill (ed.), Learning to Change? The Role of Identity and Learning Careers in Adult Education (pp. 17-32). Frankfurt: Peter Lang.

Friend, M. and Cook, L. (1992). Interactions: Collaboration Skills for School Professionals. New York: Longman Publishing Group.

Fullan, M. (1993). Change Forces: Probing the Depths of Educational Reform. London: Falmers Press.

Gadermann, A. M., Guhn, M., Schonert-Reichl, K. A., Hymel, S., Thomson, K. and Hertzman, C. (2016). A population-based study of children's well-being and health: The relative importance of social relationships, health-related activities, and income. Journal of Happiness Studies, 17(5), 1847-1872.

Granovetter, M. (2005). The impact of social structure on economic outcomes. The Journal of Economic Perspectives, 19(1), 33-50.

Haslam, C., Cruwys, T., Haslam, S. A. and Jetten, J. (2017). Social connectedness and health. In N.A Pachana (ed.), Encyclopedia of Geropsychology, (pp. 2174-2182). Singapore: Springer Verlag.

Holmes, L. (2013). Competing perspectives on graduate employability: Possession, position or process? Studies in Higher Education, 38(4), 538-554.

Jackson, D. (2014). Factors influencing job attainment in recent bachelor graduates: Evidence from Australia. Higher Education, 68(1), 135-153.

Johnson, D. W. and Johnson, R. T. (1990). Social skills for successful group work. Educational Leadership, 47(4), 29-33.

Jose, P. E., Ryan, N. and Pryor, J. (2012). Does social connectedness promote a greater sense of well-being in adolescence over time? Journal of Research on Adolescence, 22(2), 235-251.

Kaplan, A. M. and Haenlein, M. (2010). Users of the world, unite! The challenges and opportunities of social media. Business Horizons, 53(1), 59-68.

Lancaster, T. (2016). Teaching students about online professionalism: Enhancing student employability through social media. In V. Benson and S. Morgan (eds), Social Media and Networking: Concepts, Methodologies, Tools, and Applications (pp. 1784-1805). Hershey: IGI Global.

Lave, J. and Wenger, E. (1991). Situated Learning: Legitimate Peripheral Participation. Cambridge: Cambridge University Press.

Lave, J. and Wenger, E. (1998). Communities of Practice: Learning, Meaning, and Identity. Cambridge: Cambridge University Press.

Leimeister, J. M. (2010). Collective intelligence. Business and Information Systems Engineering, 2(4), 245-248. 
Lewis, A. (1953). Health as a social concept. The British Journal of Sociology, 4(2), 109-124.

Madge, C., Meek, J., Wellens, J. and Hooley, T. (2009). Facebook, social integration and informal learning at university: 'It is more for socialising and talking to friends about work than for actually doing work'. Learning, Media and Technology, 34(2), 141-155.

Mahoney, D. and Siyambalapitiya, S. (2017). Community-based interventions for building social inclusion of refugees and asylum seekers in Australia: A systematic review. Journal of Social Inclusion, 8(2), 66-80.

Manderson, L. (1948). The social context of wellbeing. In L. Manderson (ed.), Rethinking Wellbeing (pp. 1-25). Netley, South Australia: Griffin Press.

Mascia, D., Magnusson, M. and Björk, J. (2015). The role of social networks in organizing ideation, creativity and innovation: An introduction. Creativity and Innovation Management, 24(1), 102-108.

McCrea, R., Walton, A. and Leonard, R. (2016). Developing a model of community wellbeing and resilience in response to change. Social Indicators Research, 129(1), 195-214.

Mitchell, C. and Sackney, L. (2011). Building and leading within learning ecologies. In T. Townsend and J. MacBeath (eds), International Handbook of Leadership for Learning (pp. 975-990). Dordrecht: Springer.

Nikitkov, A. and Sainty, B. (2014). The role of social media in influencing career success. International Journal of Accounting and Information Management, 22(4), 273-294.

Olaniyan, D. and Okemakinde, T. (2008). Human capital theory: Implications for educational development. Pakistan Journal of Social Sciences, 5(5), 479-483.

Power, J., Schofield, M. J., Farchione, D., Perlesz, A., McNair, R., Brown, R. ... Bickerdike, A. (2015). Psychological wellbeing among same-sex attracted and heterosexual parents: Role of connectedness to family and friendship networks. Australian and New Zealand Journal of Family Therapy, 36(3), 380-394.

Reis, H. T. (1984). Social interaction and well-being. Personal Relationships, 5(1984), 21-45.

Rossin, D. and Hyland, T. (2003). Group work-based learning within higher education: An integral ingredient for the personal and social development of students. Mentoring and Tutoring, 11(2), 153-162.

Seibert, S. E., Kraimer, M. L. and Liden, R. C. (2001). A social capital theory of career success. Academy of Management Journal, 44(2), 219-237.

Siemens, G. (2005). Connectivism: A learning theory for the digital age. International Journal of Instructional Technology and Distance Learning, 2(1) (online). 
Song, H., Zmyslinski-Seelig, A., Kim, J., Drent, A., Victor, A., Omori, K. and Allen, M. (2014). Does Facebook make you lonely? A meta analysis. Computers in Human Behavior, 36, 446-452.

Tocher, N., Oswald, S. L. and Hall, D. J. (2015). Proposing social resources as the fundamental catalyst toward opportunity creation. Strategic Entrepreneurship Journal, 9(2), 119-135.

Tomlinson, M. (2012). Graduate employability: A review of conceptual and empirical themes. Higher Education Policy, 25(4), 407-431.

Tomlinson, M. (2017). Forms of graduate capital and their relationship to graduate employability. Education+Training, 59(4), 338-352.

Utz, S. and Breuer, J. (2017). The relationship between use of social network sites, online social support, and well-being: Results from a 6-wave longitudinal study. Journal of Media Psychology, 29(3), 115-125.

Verduyn, P., Ybarra, O., Résibois, M., Jonides, J. and Kross, E. (2017). Do social network sites enhance or undermine subjective well-being? A critical review. Social Issues and Policy Review, 11(1), 274-302.

Yorke, M. (2006). Employability in Higher Education: What It Is - What It Is Not. York: The Higher Education Academy. 